\title{
The Glass Transition Temperature of Poly(phenylene oxide): Annealing and Filler Effects
}

\author{
Luigi Nicolais and Robert F. LANDeL* \\ Istituto di Principi di Ingegneria Chimica, University of Naples, Itary. \\ Paolo Giordano-Orsini \\ Istituto di Chimica Applicata, University of Naples, Italy.
KEY WORDS Glass Temperature / Poly(2,6-dimethyl-p-phenylene oxide) / Annealing / Glass Bead Composites / Shear Moduli / Free Volume / Filler /

We wish to report some observations on the $T_{\mathrm{g}}$ behavior of "poly(phenylene oxide)" PPO (poly(2,6-dimethyl-p-phenylene oxide), both unfilled and containing varying ammounts of glass beads as filler.

The $T_{\mathrm{g}}$ of unfilled PPO is usually given as $210^{\circ} \mathrm{C}^{1}$ But this is for specimens which have been molded from the powder supplied by the manufacturer. If this powder is used in DTA experiments, without prior heating, a transition is found at $234^{\circ} \mathrm{C}$. On cooling and reheating the same specimen in the apparatus, the transition occurs at a lower temperature and with reduced intensity, as shown in Figure. 1. If the sample is annealed at $300^{\circ} \mathrm{C}$ for varying ammounts of time, $T_{\mathrm{g}}$ drops rapidly in the first few minutes and tend to level off at the usual value, as seen in Figure 2. The curves of Figure 1 were obtained with a du Pont Thermoanalyzer, model 900 , using a heating rate of $20^{\circ} \mathrm{C} / \mathrm{min}$. The samples, previously dried in a dessicator for at least $24 \mathrm{hr}$ at room temperature, were exposed to air during the measurements. Just above the endo-thermic peak, which we believe represents $T_{\mathrm{g}}$, an apparent exo-thermic peak occurs. It is apparently this peak which is reported ${ }^{2}$ as a melting point, with $T_{\mathrm{m}}=270^{\circ} \mathrm{C}$.

Since it is unwise to base $T_{\mathrm{g}}$ estimates solely on DTA data, DSC measurements were also

* Senior Fulbright Research Scholar, 1971-1972. On leave from Jet Propulsion Laboratory, California Institute of Technology, U.S.A. made (Perkin-Elmer DSC-1) with a similar heating rate of $16^{\circ} \mathrm{C} / \mathrm{min}$ and with more careful control of the baseline. A nitrogen blanket was employed, which reduced but did not eliminate oxygen. A typical first heat cycle is shown in Figure 3. The DSC results confirm the DTA measurements: $T_{\mathrm{g}}$ at about $230^{\circ} \mathrm{C}$ with an exo-thermic peak at $270^{\circ} \mathrm{C}$, and the same shift in $T_{\mathrm{g}}$ after exposure to $300^{\circ} \mathrm{C}$. These results raise a number of questions: Why is $T_{\mathrm{g}}$ decreased by the heating, what is the origin of the high temperature peak and does one "transition" effect the other. There are

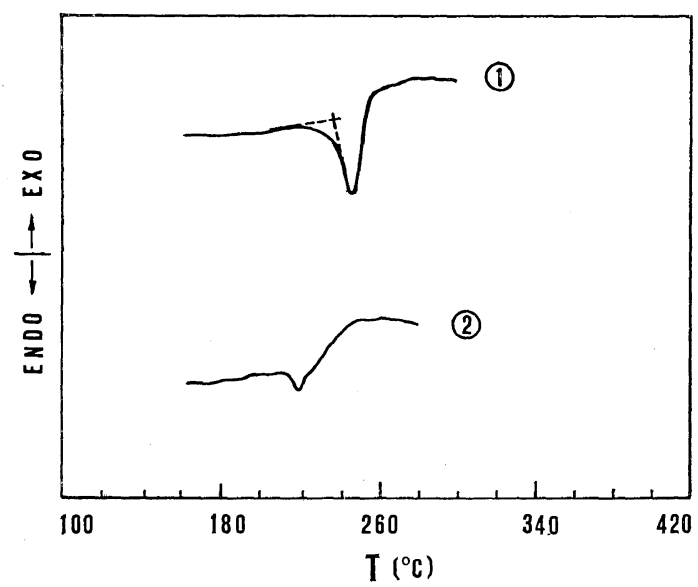

Figure 1. DTA curves for (1) powder, as supplied, and (2) same sample after a $2 \mathrm{~min}$ annealing at $300^{\circ} \mathrm{C}$, cooling to $150^{\circ} \mathrm{C}$ and immediately rerun. $T_{\mathrm{g}}$ estimated from base line and low-temperature side of peak as shown. 


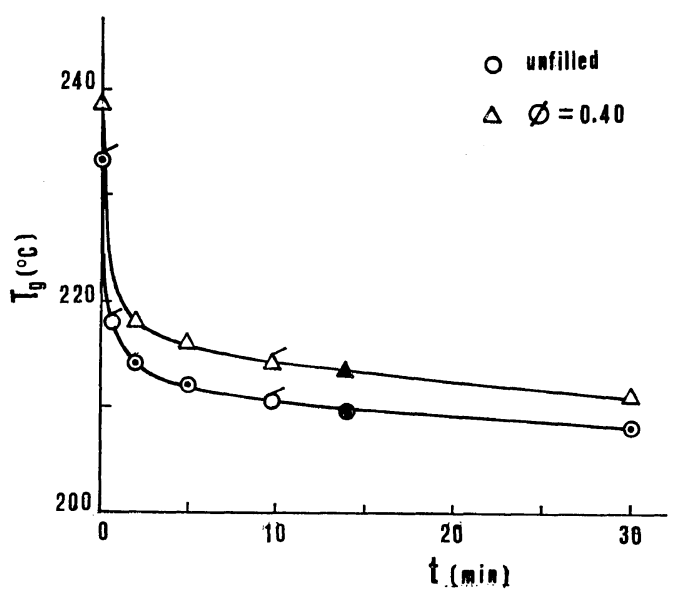

Figure 2. Change in $T_{\mathrm{g}}$ with time of annealing at $300^{\circ} \mathrm{C}$, as determined by DTA (unflagged points) and DSC (flagged). Filled point-sample shaved from a conventionally molded sheet.

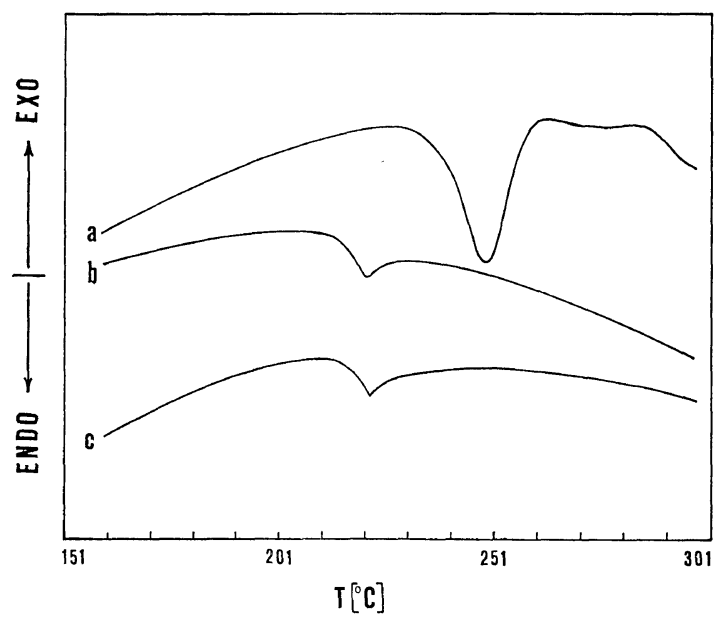

Figure 3. Portion of the DSC curve for the powdered PPO, showing (a) the high-temperature peak, (b) the same region after heating to $300^{\circ} \mathrm{C}$, cooling and rerunning, and (c) the same region after annealing $1 \mathrm{hr}$ at $272^{\circ} \mathrm{C}$, cooling to $150^{\circ} \mathrm{C}$ and rerunning.

several possible answers to each of these, which can be checked by appropriate experiments.

$T_{\mathrm{g}}$ can be changed by frozen-in stresses and by the presence of small-molecule impurities, either preexisting or induced by the heating. It might possibly be affected by the degree of crystallinity of the sample. On the other hand the apparent change in $T_{\mathrm{g}}$ might be only an artifact, since the experimentally observed quantities of temperature difference (DTA) and rate of heat input (DSC) depend on heat transfer, thermal conductivity and specific heat as well as on the changes in phase or in heat capacity per se.

If $T_{\mathrm{g}}$ has been altered by the relief of frozenin stresses, the magnitude of the drop would have to imply enormously high compressive stresses in the powder granules. The point is easily checked by heating just below $T_{\mathrm{g}}$, to $234^{\circ} \mathrm{C}$ and immediately cooling. Although the material is still in the glassy state at this temperature, it is now so close to $T_{\mathrm{g}}$ that such high stresses must relieve themselves. Thus when the powder is reheated, $T_{\mathrm{g}}$ should again be reduced. However, experiment shows that it is not, which eliminates this source of change. The presence of pre-existing small molecule impurities is also an unlikely source of the change in $T_{\mathrm{g}}$. They normally plasticize a polymer or lead to separate transitions. In the first case, their removal by heat would shift $T_{\mathrm{g}}$ to higher, not lower temperature (unless they act as antiplasticizers); in the second case, the main chain $T_{\mathrm{g}}$ should remain unchanged.

The use of two different (though admittedly related) experimental techniques for determining $T_{\mathrm{g}}$ strongly argues against experimental artifacts. Moreover, the value of $210^{\circ}$ for the heated material agrees well with that deduced from mechanical property tests on molded specimens. Clash-Berg $G(10)$ data are shown in Figure 4 where it can be seen that the Tobolsky $T_{\mathrm{i}}$ value is about $210^{\circ} \mathrm{C}$.

The lower $T_{\mathrm{g}}$ of the heated material probably results from degradation. Thus, Ehlers, Frish and Powell ${ }^{3}$ and Davis ${ }^{4}$ show that an initial weight increase occurs as samples are heated in air or oxygen, the amount of the increase being in accord with an oxygen uptake of $1.8 \times 10^{2}$ $\mathrm{cm}^{3} / \mathrm{g} / \mathrm{hr}$ at $300^{\circ} \mathrm{C}$, a value obtained by extrapolation from Davis' Figure 3. Conley ${ }^{5}$ has also pointed out the rapid oxygen attack on specimens (presumably in the form of films), noting that at $225^{\circ} \mathrm{C}$ an induction period is followed by very vigorous reaction. We calculate from Davis' data that the uptake amounts to roughly one mole of oxygen per chain, which should suffice to give the few percent of low- 


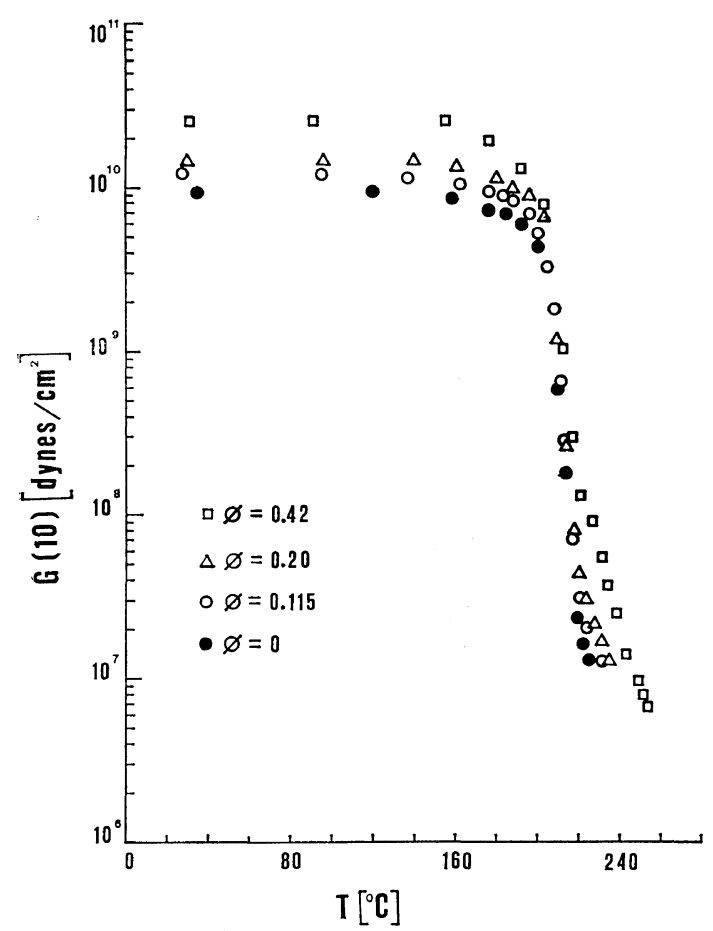

Figure 4. Clash-Berg $G(10)$ modulus data for molded specimens of PPO, for different filler levels.

molecular-weight products which would be required to lower $T_{\mathrm{g}}$ by $25^{\circ} \mathrm{C}$.

The fact that the same initial value of $T_{\mathrm{g}}$ of about $234^{\circ} \mathrm{C}$ is found in experiments run in both air (DTA) and under a nitrogen blanket (DSC) indicates that only traces of oxygen are required. If oxydative degradation is the culprit, compressing the powder at room temperature before test should reduce the effect. Thin sheets were therefore prepared in this way and material for the DTA test was obtained by shaving in the usual way. An even higher $T_{\mathrm{g}}$ of $243^{\circ} \mathrm{C}$ was obtained. This same specimen was rerun after holding it at $300^{\circ} \mathrm{C}$ in the apparatus for $5 \mathrm{~min}$. $T_{\mathrm{g}}$ again decreased-to $220^{\circ} \mathrm{C}$; presumably its $T_{\mathrm{g}}$ would also drop to about $210^{\circ} \mathrm{C}$ with further annealing at $300^{\circ} \mathrm{C}$.

The high temperature peak, seen in Figure $3 a$, could be interpreted as a crystalline melting, for when the sample is reheated the peak has disappeared, as in Figure $3 b$, i.e., as if the crystallites had melted but not reformed in the time available.
To investigate this region more closely, samples were heated to $258^{\circ} \mathrm{C}$, i.e., well below the beginning of the upper peak, immediately cooled and then heated to $300^{\circ} \mathrm{C}$. A second sample was heated to $272^{\circ} \mathrm{C}$, the temperature of the peak, and annealed for $1 \mathrm{hr}$ before cooling and reheating to $300^{\circ} \mathrm{C}$.

If the peak is due to crystallinity, the first experiment should not change it, while in second case annealing should permit further crystallization if the preexisting crystallinity were not the equilibrium value for that temperature. Subsequent reheating to $300^{\circ} \mathrm{C}$ should then show either no or an enhanced thermal effect, depending on whether the crystallinity remains constant or increases. In actual fact, the first experiment leads to a virtual disappearance of the peak while in the annealed sample it disappeared completely, Figure $3 \mathrm{c}$. These results argue that the peak is not due to crystallinity at all. The $258^{\circ} \mathrm{C}$ exposure could only have changed the peak if the crystallites were in a highly metastable condition. However, the annealing should then have permitted regrowth on the residual stable nuclei. As a further check, X-ray diffraction patterns were taken on the fresh powder, before and after heating to $300^{\circ} \mathrm{C}$ and after annealing at $272^{\circ} \mathrm{C}$ for $1 \mathrm{hr}$. No evidence for crystallinity could be seen by this admittedly less sensitive technique.

Prior experience with the analysis of inorganic glasses and semicrystalline materials ${ }^{6}$ suggests that this peak is simply due to the change of heat transfer to the sample as the sample flows above $T_{\mathrm{g}}$. All of the results are consistent with this mechanism-heating to $172^{\circ} \mathrm{C}$ and immediate cooling permits only partial fusion with a correspondingly small decrease in "endo-thermicity;" annealing for $1 \mathrm{hr}$ permits added flow and elimination of the peak (Figure 3c).

Finally, we note that in these two experiments the value of $T_{\mathrm{g}}$ after reheating is nearly constant, showing that changes in the high-temperature peak have had no effect on it. Having established $T_{\mathrm{g}}$ for the powder and molded material, we now consider the effect of a filler. When 40 vol $\%$ of glass beads is added to the polymer, the glass temperature is raised about $4^{\circ} \mathrm{C}$. This effect is independent of the anneal- 


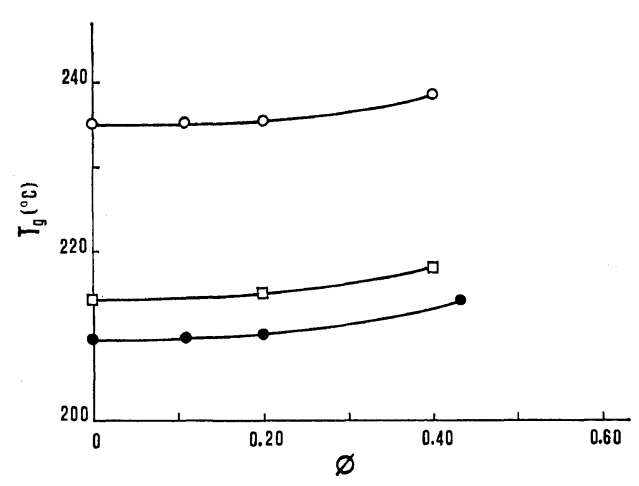

Figure 5. Increase in $T_{\mathrm{g}}$ of PPO (DTA measurement) with filler content for $\bigcirc$ the powdered material; $\square$ the same material after heating to $300^{\circ} \mathrm{C}$ for $3 \mathrm{~min}$; samples shaved from molded pieces.

ing time and, more importantly, occurs in the simple physical mixture of the two components (Figure 2). This means that since the PPO is in the glassy state until $T_{\mathrm{g}}$, there cannot be polymer adsorption on the glass. Hence the usual explanation of a modification of chain motion and free volume by the filler particles cannot be invoked here.

When varying bead concentrations are employed, results such as shown in Figure 5 are obtained. Here the results of the first and second heating of the mixed powders are compared with results from specimens which were prepared by mixing and molding at $285^{\circ} \mathrm{C}$ in the usual way. The material used for the DTA measurements was shaved off the molded piece with a razor blade. The much higher $T_{\mathrm{g}}$ of the virgin powder is evident in all compositions. Moreover, the effect of the glass on the apparent $T_{\mathrm{g}}$ is the same in all cases and again argues against a real effect by the beads.

We can offer no convincing explanation for the effect of the beads. Since the DTA apparatus measures the temperature difference between a reference (glass beads) and the sample, perhaps it is a question of heat capacity and heat transfer plus thermal conductivity in the mixed system. The latter seems doubtful however because the same $T_{\mathrm{g}}$ is found with the sample temperature leading and lagging the reference temperature. Moreover, DSC gives the same result (Figure 2). More experiments with three-phase systems (two powders and air) are indicated.

As a first step, differential DSC has been attempted, using powdered PPO in the reference cell instead of air, and the $20 \%$ beads $-80 \%$ PPO in the sample holder. A slight change in the slope of the base line occurs in the region of $T_{\mathrm{g}}$, but with the present sensitivity of the apparatus it is impossible to distinguish whether there is a change in $T_{\mathrm{g}}$, even if much reliance could be placed on the small change observed. The high temperature peak shows clearly, however, though with reversed sign because of the larger amount of polymer in the reference cell.

The negligible effect of the filler on $T_{\mathrm{g}}$ is also shown in the modulus data, Figure 4. The beads clearly enhance the glassy modulus, as expected, and are tending to increase the modulus at the foot of the transition zone, as it should. The location of the transition zone is unchanged, however. Analogously no effect of the glass beads on the $T_{\mathrm{g}}$ of polystyrene has been reported by Mills ${ }^{7}$ while small effect of a filler on the transition temperature have been reported by Landel $^{8}$ for glass beads in PIB or by Schwarzl ${ }^{9}$ for potassium chloride in a polyurethane rubber. Droste and Di Benedetto ${ }^{10}$ using DTA also report only a small effect on $T_{\mathrm{g}}-4$ or $5^{\circ} \mathrm{C}$ at $40 \%$ - for beads in a phenoxy polymer.

This small change in $T_{\mathrm{g}}$ is in contrast to earlier data of $\mathrm{Landel}^{11}$ reporting a large increase of $T_{\mathrm{g}}$ for ammonium perchlorate in polyurethane rubbers similar to that used by Schwarzl, using linear expansion coefficient measurement to determine $T_{\mathrm{g}}$.

In this case, the postulated attachment of the chains to the filler could well be real, since the $\mathrm{NH}$ moiety of the urethane group or of any traces of urea groups can fit into the crystal lattice, replacing the $\mathrm{NH}_{4}^{+}$group. The possibility cannot be ruled out, however, that small amounts of the salt have dissolved in the polymer and modified its $T_{\mathrm{g}}$, as can happen with lithium salts in poly(propyleneoxide). ${ }^{12}$

\section{REFERENCES}

1. G. Allen, M. W. Coville, R. M. John, and R. F. Warren, Polymer, 11, 492 (1970)

2. F. E. Karasz and J.M. O'Reilly, Polymer Let- 
ters, 3, 561 (1965).

3. G. F. L. Ehlers, K. R. Frisch, W. R. Powell, J. Polym. Sci., Part A-1, 7, 2931 (1969).

4. A. Davis, Makromol. Chem., 132, 23 (1970).

5. R. T. Conley, J. Macromol. Sci., A-1, 1, 81 (1967).

6. A. Buri, A. Marotta, and P. Giordano-Orsini, Ceramurgia, 1, 169 (1971).

7. N. J. Mills, J. Appl. Polym. Sci., 15, 2791 (1971).

8. R. F. Landel, Trans. Coc. Rheol., 2, 53 (1958).
9. C. W. Van der Wal, H. W. Bree, and F. R. Shwarzl, J. Appl. Polym. Sci., 9, 2143 (1965).

10. D. H. Droste and A. T. Di Benedetto, ibid., 13, 2149 (1969).

11. R. F. Landel, "Bimonthly Summary, Aug.Sept., 1958,' Jet Propulsion Laboratory, Pasadena, California, Nov. 30, 1958.

12. E. Cuddihy and J. Moacanin, J. Polym. Sci. Part C, 14, 313 (1966). 